\title{
Formação docente, metodologias ativas e problematização: diálogos com Paulo Freire
}

\author{
Teacher training, active methodologies and problematization: dialogues with \\ Paulo Freire
}

\author{
Thiago Jovane Nascimento ${ }^{1}$ \\ Sonia Regina de Souza Fernandes ${ }^{2}$
}

\begin{abstract}
Resumo
Este texto é resultante de uma pesquisa bibliográfica conforme Gil (1994), que objetiva apresentar discussões e reflexões acerca da formação docente, em diálogo com o pensamento freireano. Contemplamos as metodologias ativas da problematização (PBL e Problematização pelo arco de Mangarez) como um dos possíveis princípios da formação docente, o que perpassa também as discussões acerca do currículo. Apontamos o currículo globalizante/integrado como o mais adequado a essa proposta. Como abordagem temática freireana, para a construção de um currículo em blocos temáticos, sinalizamos a possibilidade do uso dos Três Momentos Pedagógicos (DELIZOICOV; ANGOTTI; PERNAMBUCO, 2002), em articulação com as metodologias ativas da problematização. Prosseguimos com a caracterização da pedagogia tradicional, em relação à qual tanto o pensamento freireano quanto às metodologias ativas se constituem enquanto uma reação. Por fim, concluímos que repensar a formação docente, numa relação dialógica-problematizadora, tem como finalidade maior a transformação social, na construção de uma sociedade mais justa e fraterna.
\end{abstract}

Palavras-chave: Paulo Freire. Metodologias Ativas. Currículo. Formação Docente.

\begin{abstract}
This text is the result of a bibliographical research Gil (1994), which looks at discussions and reflections on teacher education, in dialogue with Freire's thought. We contemplate the active problematization methodologies (PBL and Problematization through the Mangarez arc) as one of the possible principles of teacher education, which also permeates the discussions about the curriculum. We point out the globalizing/integrated curriculum as the most suitable for this proposal. As a Freirean thematic approach, for the construction of a curriculum in thematic blocks, we indicate the possibility of using the Three Pedagogical Moments (DELIZOICOV; ANGOTTI; PERNAMBUCO, 2002), in conjunction with the active problematization methodologies. We continue with the characterization of traditional pedagogy, in relation to which both Freirean thought and

\footnotetext{
${ }^{1}$ Graduação em Letras pela Universidade do Vale do Itajaí/UNIVALI. Mestrando em Educação pelo Instituto Federal Catarinense. E-mail: tj.nascimento@hotmail.com.

${ }^{2}$ Mestrado e Doutorado em Educação pela Universidade do Vale do Rio dos Sinos/UNISINOS. Reitora do Instituto Federal Catarinense. E-mail: sonia.fernandes@ifc.edu.br.
} 


\section{-Revista de Iniciação à Docência, v.6, n.2, 2021- \\ Publicação: dezembro, 2021 - ISSN 2525-4332}

active methodologies are constituted as a reaction. Finally, we conclude that rethinking teacher education, in a dialogical-problematizing relationship, has as its main objective social transformation, in the construction of a more just and fraternal society.

Keywords: Paulo Freire. Active methodologies. Curriculum. Teacher training.

\section{Introdução}

Neste artigo, propomos refletir sobre a formação docente e o currículo, tendo como um dos princípios as metodologias ativas da problematização, em diálogo com o pensamento freireano. Trata-se de uma pesquisa bibliográfica, que perspectiva discussões e reflexões acerca da formação docente. Consoante Gil (1994), este tipo de pesquisa permite grande alcance de informações, a partir de diversas publicações, o que otimiza a conceituação e a construção do objeto de estudo. Para tanto, partimos do legado de Paulo Freire: o insigne educador brasileiro que, entre tantas contribuições, em suas obras enfatiza que "a educação é um ato político" (FREIRE, 2019c, p. 83, grifos no original).

Tendo em vista a complexidade da educação, que é sobretudo um ato político, a formação docente da mesma forma é perpassada por diversos determinantes e inúmeras questões transversais, que extrapolam relações de causa e efeito. Aspectos culturais e sociais, políticos e econômicos interferem na formação do professor, para além da própria constituição e formação individual do sujeito que se insere em um curso de licenciatura visando seguir a carreira docente.

Somados a estas dimensões, existem os aspectos legais, os quais têm por base a Constituição Federal (BRASIL, 1988). O regime colaborativo da Carta Magna foi reiterado na LDB (1996), a qual norteia inclusive a formação docente. Por conseguinte, o Parecer 09/2001 (BRASIL, 2001) conferiu a singularidade própria aos cursos de licenciatura. Ao longo do século XXI, diretrizes e pareceres delinearam o curso de pedagogia e a formação de professores. De maneira geral, a atual conjuntura legal se encontra num cenário de padronização - através de bases curriculares, como a BNCC (2017), a BNC-Formação (2019) e a BNC-Formação Continuada (2020); de verificação de aprendizagem (através de testes de larga escala); e de eventual responsabilização pelos resultados. Esse alinhamento, que vai da educação básica à formação docente, pode gerar um sistema meritocrático, no qual "os resultados das avaliações passam a guiar a vida escolar" (FREITAS, 2018, p. 82). Desse modo, é possível dizer que a complexidade da formação de professores envolve várias dimensões - objetivas e subjetivas, e as discussões em torno da mesma, requerem cotejá-las à luz dos tensionamentos dialéticos.

Freire (2019C) nos aponta que: “Nós somos seres indiscutivelmente programados mas, de modo nenhum, determinados. E somos programados sobretudo para aprender, como salienta François Jacob." (FREIRE, 2019c, p. 185) Assim, neste texto propomos refletir sobre as contribuições do pensamento freireano para a formação docente, bem 


\section{-Revista de Iniciação à Docência, v.6, n.2, 2021- \\ Publicação: dezembro, 2021 - ISSN 2525-4332}

como as questões curriculares que envolvem os processos de formação, tendo como um dos princípios as metodologias ativas, em especial as metodologias da problematização.

Negando o determinismo, vislumbrando a possibilidade de transformação da realidade, concordamos com Freire (2019c), quando afirma que a tomada de distância é necessária, para que se veja melhor o objeto em questão. Ou seja, é preciso distanciar-se para desnaturalizar os fenômenos sociais, que são tidos por comuns. De outra forma, continuaremos repetindo as mesmas coisas, porque sempre foram assim e sempre serão. "A dialeticidade entre prática e teoria deve ser plenamente vivida nos contextos teóricos da formação de quadros." (FREIRE, 2019c, p. 110) Assim, a formação crítica dos docentes passa pelo constante movimento dialético, tomando o binômio teoria-prática como indissociável. Para além da padronização ocasionada pelos documentos legais, perspectivamos contribuir para a formação docente de maneira dialógica, coletivamente, já que na perspectiva freireana $(2005 ; 2019 c)$ o caráter problemático é inerente à decodificação, cujo significado é amplo e plural.

Neste contexto, vários estudos têm discutido o uso de metodologias ativas nos processos de ensino e aprendizagem, em nível superior, no âmbito da formação profissional em saúde (FINI, 2018; CALDARELLI, 2017; ROMAN, et al., 2017; SANTOS et al., 2017). Em uma revisão integrativa da literatura, que analisou publicações realizadas entre 2013 e 2018, incluindo artigos, teses, dissertações e capítulos de livro, ficou constatado que os principais temas de investigação na área da educação médica referem-se ao uso de tecnologias digitais e as metodologias ativas: "Tal forma de conduzir o processo de ensino e aprendizagem tem-se destacado como tendência de estratégia nas instituições de ensino superior [...]". (POTT, JUNIOR, 2019, p. 139).

Constatando o reconhecimento internacional de Paulo Freire, insigne educador brasileiro que defende uma educação libertadora e promotora de transformação social, é possível perceber que suas reflexões são utilizadas nos mais diversos campos de intervenção e produção do conhecimento (MAGALHÃES, 2012). Sendo alguns dos princípios básicos freireanos a dialogicidade e a problematização, tomamos por primícia a condição de inconclusão dos seres humanos em busca do ser. "Diante disso, observa-se que Paulo Freire tem uma contribuição histórica para a formação humana e para a organização de formas de educação libertadoras, reconhecida internacionalmente." (SPOHR; DALSOTTO; CORREA, 2021, p. 18).

Assim, propomos uma visão dialógico-problematizadora da formação docente. No sentido da negação da neutralidade, já que o ato pedagógico é um ato político (FREIRE, 2019c), não tomamos as metodologias ativas por técnicas de ensino, a serem usadas de maneira pontual e limitada. Para Paulo Freire, a conscientização tem dupla função nos processos educativos: ao mesmo tempo é metodologia e objetivo. Nessa perspectiva, refletimos sobre as metodologias da problematização, em oposição à pedagogia tradicional na formação de professores. Para tanto, buscamos relacionar as metodologias 


\section{-Revista de Iniciação à Docência, v.6, n.2, 2021- \\ Publicação: dezembro, 2021 - ISSN 2525-4332}

ativas às ideias de Paulo Freire, com vistas à formação docente. Por conseguinte, tensionamos as formas de organização curricular para a formação docente, perspectivando o currículo globalizante/integrado (ANASTASIOU, 2005; BERNSTEIN, 1977). Para esse tipo de currículo, organizado em blocos temáticos, sugerimos os 3MP(DELIZOICOV; ANGOTTI; PERNAMBUCO, 2002), os quais articulamos com a aprendizagem baseada em problemas (PBL e Problematização pelo arco de Manguerez) como uma possibilidade metodológica.

\section{O currículo globalizante/integrado como uma perspectiva para a formação docente}

Os debates sobre a formação de professores não são recentes. No entanto, ganham relevo na conjuntura atual, em que políticas públicas, como a BNC-Formação (BRASIL, 2019), propõem mudanças na formação de professores, a partir de dez competências gerais, em consonância com a BNCC (BRASIL, 2017). Por outro lado, a LDB (BRASIL, 1996) aponta como conceito de docência a formação específica, articulada com a prática em sala de aula. Nesse sentido, discutimos as metodologias ativas da problematização como um dos princípios da formação docente, na perspectiva do currículo globalizante/integrado, em diálogo com o pensamento de Paulo Freire. Evocamos as palavras do eminente educador brasileiro:

\footnotetext{
No processo de alfabetização, portanto, esses dois polos devem ser levados em consideração: de um lado, as condições objetivas, sociais, históricas; de outro, as condições individuais dos que participam do processo de alfabetização. Os resultados mais ou menos positivos não dependem apenas do gosto de quem quer aprender, porque, inclusive, este está também na dependência do social. (FREIRE, 2019a, p. 52).
}

A partir dessa compreensão, transpomos as ideias da citação acima para o processo de formação docente. Por conseguinte, negamos o determinismo e acreditamos na possibilidade de mudanças. O modelo fragmentado e não crítico de formação docente pode dificultar a aprendizagem e o desenvolvimento global do professor. Assim, formado pela pedagogia tradicional, se não encontrar possibilidades de reflexão e ressignificação durante os processos formativos, o professor acaba reproduzindo o ensino que foi base de sua formação. Nesse sentido, repete a educação bancária (FREIRE, 2005), por mimese, o que dispensa a reflexão teórica.

A crítica à pedagogia tradicional se encontra nos fundamentos da pedagogia freireana: "Por isso também é que ensinar não pode ser um puro processo, como tanto tenho dito, de transferência de conhecimento da ensinante ao aprendiz. Transferência mecânica de que resulte a memorização maquinal que já critiquei” (FREIRE, 2019c, p. 64). Dessa forma, Freire defende que para a formação de um sujeito crítico, é necessário um ensino que também seja crítico, oposto ao ensino tradicional. 


\section{-Revista de Iniciação à Docência, v.6, n.2, 2021- \\ Publicação: dezembro, 2021 - ISSN 2525-4332}

Em consonância com as ideias de Paulo Freire, hodiernamente as metodologias ativas se constituem como uma reação ao ensino tradicional. "Assim, contrapondo ao método tradicional, os papéis e funções do professor e aluno se revertem" (SANTOS; CABRAL, BRITO, 2019 p. 90). Nessa vertente, as metodologias ativas se apresentam como uma oposição à pedagogia tradicional, a qual compreende o aluno enquanto sujeito passivo da aprendizagem, como fica evidente no seguinte excerto:

O que as distingue das práticas atuais de ensino é que - na perspectiva ativa - o desenvolvimento da aprendizagem coloca o estudante como precursor da construção do seu conhecimento, ou seja, o termo 'ativa' relaciona-se com o protagonismo e autonomia do aluno (MORAIS, 2019, p. 59).

Superação da pedagogia tradicional, protagonismo e autonomia do educando: eis os primeiros pontos em comum entre as ideias freireanas e as metodologias ativas. Outrossim, Paulo Freire já delineava os princípios da Aprendizagem Baseada em Problemas (ABP) ou Problem-Based Learning (PBL), consoante Berbel (1999). Essa autora também afirma que tanto o PBL quanto o método de alfabetização freireano constituem uma oposição à pedagogia tradicional, a qual está fundamentada na transmissão de conhecimento. Mas, afinal, o que vem a ser a pedagogia tradicional?

Colocamos de maneira sucinta o que Reis Filho (1995, p. 68) caracteriza como pedagogia tradicional: Simplicidade, análise e progressividade (iniciar pelo mais simples avançando para o mais complexo, dividindo os elementos do conhecimento); formalismo (lógica dedutiva); memorização; autoridade (centrada no professor); emulação (que vem a reforçar o princípio da autoridade); intuição (dados sensíveis à observação do aluno, como ilustrações, objetos e figuras).

Vale ressaltar que não compreendemos a formação docente como neutra ou apolítica. Coadunamos com Paulo Freire, ao dizer que a educação é um ato político. Não existe, portanto, neutralidade nos processos educativos. O professor precisa ser coerente com a própria opção, que é política. A falsa neutralidade, aliás, traz implícito o aceite às determinações da classe dominante: não traz, por isso, uma formação crítica. Assim, para além da formação docente pela pedagogia tradicional, refletimos sobre a possibilidade das metodologias da problematização como um dos princípios formativos, em diálogo com o pensamento freireano. Dessa maneira, a formação docente inicia partindo da prática, discutindo a teoria e à própria prática retornando, no intuito de transformá-la:

[...] a profissão de professor implica envolver-se com a totalidade do mundo dos homens, o universo dos conhecimentos, das ciências e cultura, o universo do trabalho e das tecnologias, o universo das lutas de mulheres e homens para construir suas vidas em sociedade com seus aspectos de solidariedade e com suas relações políticas. (FREIRE, 2019c, p. 18).

Dessa forma, ao refletir sobre uma formação na qual o futuro professor se envolva com a totalidade dos conhecimentos, problematizando a pedagogia tradicional e a própria formação (pautada nas legislações e perpassada por diversos determinantes), 


\section{-Revista de Iniciação à Docência, v.6, n.2, 2021- \\ Publicação: dezembro, 2021 - ISSN 2525-4332}

consequentemente refletimos também sobre o currículo, que é uma das dimensões da formação docente, alvo de constantes reformulações legais nos últimos anos, como já apontamos. Um currículo não fragmentado e contextualizado, contemplando as metodologias ativas da problematização, pode contribuir para a integração dos conhecimentos, bem como para uma articulação maior entre teoria e prática, entre outros aspectos. Para tanto, ao refletirmos sobre as metodologias da problematização inspiradas nos ideais freireanos para a formação docente, não consideramos a utilização de tais metodologias de maneira isolada, e sim como um dos princípios formativos.

Quando se delineia alguma mudança nos processos de ensino e aprendizagem, dificilmente a alteração pode ser implantada ignorando-se uma mudança curricular. Isso porque o currículo perpassa as relações entre professor, educando e conhecimento. Segundo Moran (2015), as metodologias ativas propõem uma mudança de paradigma, horizontalizando a relação entre professor e aluno, colocando este último como centro do processo e corresponsável pela própria aprendizagem. Esse mesmo autor (2019) também conceitua o termo metodologias ativas como um conjunto de estratégias de ensino focadas na participação efetiva dos educandos no processo de ensino e aprendizagem. Assim, os conhecimentos são interligados e a aprendizagem tem sentido para o educando.

Nessa perspectiva, um currículo que contemple as metodologias ativas da problematização, sob inspiração freireana, está em uma relação dialógica, em um movimento de teoria à prática e vice-versa. Além disso, é necessário que se tenham claros os objetivos educacionais, pois as técnicas não possuem um fim em si mesmas. Veiga (2006) assim ressalta esta ideia: "Enfatizando: toda técnica é tecida e envolvida por determinados ideais educativos. Não é a técnica que define o ideal educativo, mas o contrário" (VEIGA, 2006, p. 26). Então, é possível fazer uma aula expositiva pelo método tradicional ou pelo método da problematização, por exemplo. É possível levar os educandos ao laboratório de informática e apenas orientá-los a copiar trechos de um determinado assunto em uma página da Web prescrita pelo professor, ou levá-los a pesquisar, movidos pela curiosidade epistemológica, como uma etapa da metodologia da problematização. Anastasiou (2005) corrobora tal posicionamento:

\footnotetext{
As estratégias por si não resolvem e não alteram magicamente o processo. Poderemos ter uma aula expositiva altamente favorável ao pensamento divergente, desafiando diversas operações mentais dos alunos, e uma proposição de projetos altamente autoritária e antifavorável à construção da autonomia do aluno e à construção do conhecimento (ANASTASIOU, 2005, p. 55).
}

Um currículo apenas baseado em técnicas ou metodologias, sem ter claro um ideal educativo, pode não proporcionar aprendizagem significativa. A mera inclusão da tecnologia nos processos educativos não é certeza de inovação pedagógica. Por isso, ao lado das questões curriculares e metodológicas, acreditamos que o ideal educativo freireano possa contribuir para a formação de professores. Mas afinal, que tipo de currículo seria mais propício para o desenvolvimento das metodologias ativas da 


\section{-Revista de Iniciação à Docência, v.6, n.2, 2021- \\ Publicação: dezembro, 2021 - ISSN 2525-4332}

problematização? Diversas formas de organização curricular e abordagens temáticas já foram teorizadas e postas em prática tendo por base tanto as ideias freireanas quanto as metodologias ativas. No sentido de convergir para ambas as visões, propondo uma formação docente crítica e problematizadora, para além da pedagogia tradicional, trazemos Bernstein (1977) e Anastasiou (2005) a fim de contribuir com a discussão sobre o currículo.

Na perspectiva de Bernstein (1977), existem dois tipos de currículo: o de coleção e o integrado. O primeiro, com rígida separação entre disciplinas e a centralidade no professor, é o mais comum; de acordo com o sociólogo britânico, o segundo é menos comum. Neste, no currículo integrado, as várias áreas do saber estão subordinadas a uma ideia central. Não há hierarquia e a interdisciplinaridade é a base. Domingos (1986) também explicita esta visão de Bernstein: “[...] os vários conteúdos estão subordinados a uma ideia central que, reduzindo o isolamento entre eles, os agrega num todo mais amplo" (DOMINGOS, 1986, p. 153).

Sob esse prisma, Anastasiou (2005), também divide os currículos em dois tipos: o currículo organizado em grade, que parte da perspectiva tradicional: é aquele constituído de maneira fragmentada, com vistas à especialização; e o currículo globalizante: é estabelecido a partir da parceria entre professor e educando. De acordo com a autora, "[...] pode-se verificar que vários currículos universitários atuais seguem ainda a configuração em grade [...]" (ANASTASIOU, 2005, p. 43). Nessa perspectiva, as disciplinas são estanques, ficando sob a responsabilidade de um professor, e os estágios curriculares são geralmente no final do curso, após as disciplinas teóricas. Metodologicamente, esse tipo de currículo é "baseado na predominância da exposição do conteúdo pelo professor e da memorização dele pelos alunos, centralizados, ambos, na verificação pelos exames". (ANASTASIOU, 2005, p. 47).

Por outro lado, o currículo globalizante seria transdisciplinar, que é a integração das disciplinas, superando a fragmentação e propondo "[...] a articulação dos conteúdos curriculares a partir de projetos, pesquisa, resolução de problemas e outras atividades." (ANASTASIOU, 2005, p. 52, grifo nosso). Dessa maneira, fica evidente que esse tipo de currículo é mais adequado às metodologias da problematização. Isso não significa, entretanto, que as formas tradicionais de organização curricular ('de coleção', na perspectiva de Bernstein; 'em grade' nas palavras de Anastasiou) não permitem as metodologias ativas da problematização em relação dialógica com Paulo Freire. Afinal, como já observamos, as estratégias, por si só, não alteram os processos educativos.

Ao analisar a condição curricular das instituições que utilizam as metodologias ativas, Moran (2019), considera que elas se encontram em diferentes níveis: enquanto algumas utilizam as metodologias ativas ocasionalmente, a partir de iniciativas isoladas de professores e gestores, outras trabalham de forma integrada e sistemática. Há um terceiro grupo de instituições, entretanto, que é redesenhado pelas metodologias ativas, 


\section{-Revista de Iniciação à Docência, v.6, n.2, 2021- \\ Publicação: dezembro, 2021 - ISSN 2525-4332}

refazendo os próprios currículos. Nessa perspectiva, Anastasiou (2005) afirma: "Atualmente, muitas instituições vêm buscando integrar o currículo, porém ainda sem alterar a lógica dele" (ANASTASIOU, 2005, p. 44). Assim, a maior parte das instituições se encontram no segundo nível indicado por Moran (2019). A autora assim prossegue: "Temos verificado o esforço de professores universitários no sentido de integrar entre si o processo de ensino, o que temos chamado de transformações por aproximações sucessivas" (ANASTASIOU, 2005, p. 44). Assim, há possibilidade de atuar com metodologias da problematização no currículo tradicional, através da integração.

Acerca do currículo globalizante/integrado, corroborando o princípio da problematização, Popper (1975) assevera que os educandos devem estudar a partir de problemas, não conteúdos, pois é através de questões que a realidade se manifesta. Este autor (1997) também diz que todo o ensino deveria estimular o educando ao pensamento crítico. Sendo assim, comungamos da ideia de Apple e Beane (1997), de que um currículo globalizante/integrado, organizado em blocos temáticos a partir de problematizações, seria "um currículo democrático que convida os jovens a abandonarem o papel passivo de consumidores do conhecimento e a assumirem o papel activo de "construtores de significados"' (APPLE; BEANE, 1997, p. 41). Dessa forma, para a organização dos "blocos temáticos", apontamos como possibilidade os Três Momentos Pedagógicos (DELIZOICOV; ANGOTTI; PERNAMBUCO, 2002), que se trata de uma abordagem temática freireana. Traremos com mais detalhes os Três Momentos Pedagógicos (3MP) adiante.

Por ora, cumpre destacar que dentre as metodologias ativas que mais contribuíram para a reorganização dos currículos, o PBL se destaca. De acordo com Anastasiou (2005), "há currículos totalmente organizados em torno da resolução de situações problemáticas (PBL)" (ANASTASIOU, 2005, p. 86). As vantagens nos processos pedagógicos de um currículo globalizante/integrado com foco no $\mathrm{PBL}$ são relevantes. Severino (1998) assim se manifesta quanto às características curriculares do PBL:

Destacaríamos, em especial, aquelas decorrentes da relação pedagógica, cujo foco principal centra-se no aluno e não no docente, e o forte envolvimento com a realidade e o ambiente clínico que ele preconiza. Tais características são consonantes com a concepção de conhecimento como construção de relações significativas, cujo êxito na educação de adultos tem sido comprovado nas mais diferentes situações e campos do conhecimento em que foi aplicada. (SEVERINO, 1998, p. 47).

Nesse enfoque, o conhecimento é construído, em um movimento dialético, sendo constantemente ressignificado pelos educandos. Como o currículo é construído em conjunto, não vem pronto, a predisposição dos educandos é fundamental nos processos pedagógicos. Elaborado em um constante movimento dialético entre teoria e prática, o currículo não é totalmente previsível no que tange às experiências pedagógicas, o que requer alto envolvimento por parte dos educandos, em interação com o professor.

Por fim, apontamos que a ressignificação do currículo, que pode ser deflagrada pela implantação das metodologias ativas, não é um processo superficial. Segundo 
Anastasiou (2005), "[...] alterar a estrutura curricular não é algo simples, pois exige uma série de transformações essenciais" (ANASTASIOU, 2005, p. 54). Em síntese, as condições que a autora elenca para alterar o currículo são: profissionalização docente continuada; reorganização do tempo e das ações; aprofundamento vertical; visão processual das possíveis frustrações oriundas da flexibilização do currículo; leitura da realidade para compor a dúvida intelectual dentro dos quadros das diversas disciplinas; e o estudo das conexões, relações, construção de leis e princípios, que vão além da sala de aula.

Destacamos, assim, a construção de um currículo globalizante/integrado para a formação de professores. Enquanto opção política, está implícita a construção de uma escola democrática em tal delineamento curricular, em que a formação docente não seja perpassada pela hierarquia - criticada por Freire. "A escola democrática de que precisamos não é aquela em que só o professor ensina, em que só o aluno aprende e o diretor é o mandante todo-poderoso" (FREIRE, 2019c, p. 102). Para além de uma relação de ordem e obediência, que reproduza as relações de poder de uma sociedade de classes, a formação docente deve ser pensada, em última instância, como uma formação para a democracia.

Assim, colocamos em perspectiva uma formação docente para além da narração de conteúdos, os quais se tomados como tendo fim em si mesmos podem tornar engessados e descontextualizados os processos educativos. Para isso, um aspecto importante é problematizar a realidade, a fim de desnaturalizar os fenômenos sociais, entendê-los e agir no sentido de construir um ideal societário mais justo e democrático. Dessa forma, as metodologias ativas da problematização (PBL e Problematização utilizando o Arco de Mangarez) podem funcionar como ponto de articulação da formação docente, constituindo-se em uma possibilidade metodológica. Antes, porém, procuraremos embasar tais metodologias nas ideias freireanas, a seguir.

\section{“Eva viu a uva": reflexões sobre o sentido da formação docente}

Quem era Eva? Em que contexto ela viu a uva? Quem plantou/produziu a uva? Paulo Freire problematiza essa frase, emblemática da alfabetização descontextualizada, típica no processo bancário e da pedagogia tradicional: uma frase sem sentido, apenas para trabalhar palavras com a letra V. Assim, há de se refletir se a educação não crítica e descontextualizada faz parte da formação docente: os futuros professores apenas veem a uva ou têm possibilidade de contemplar também a parreira, discutindo sobre quem a plantou, por quê, quais as relações de produção aí envolvidas, entre outras questões? Por isso, contextualizar a teoria durante a formação do professor, fazendo com que emerja da prática, é fundamental para que o ciclo de "Eva viu a uva" seja rompido. Não obstante, é mister demarcar que Paulo Freire não fazia uso do vocábulo contextualização. Entretanto, argumenta que "[...] será a partir da situação presente, existencial, concreta, 


\section{-Revista de Iniciação à Docência, v.6, n.2, 2021- \\ Publicação: dezembro, 2021 - ISSN 2525-4332}

refletindo o conjunto de aspirações do povo, que poderemos organizar o conteúdo programático da educação". (FREIRE, 2005, p. 100).

A partir do livro Pedagogia do Oprimido, em que o capitalismo é encarado como o grande opressor, Freire não concebe a educação como preparatória para a liberdade, mas sim como uma própria prática de libertação. A educação não é uma preparação para a vida: é a própria vida - dizia ele. Com reconhecimento internacional, de grande repercussão, a Pedagogia do Oprimido (publicado pela primeira vez em 1968) apresenta os fundamentos do pensamento freireano, que se pauta na reflexão-ação, caracterizando a práxis. Unindo os fins aos meios dos processos educativos, Paulo Freire não vê os conteúdos com um fim em si mesmos, mas sim atrelados a tais ideais, munindo o sujeito de uma bagagem cultural que lhe permita atuar no sentido de emancipar-se e destruir os mecanismos de opressão da sociedade. Freire afasta-se, assim, da didática tradicional. No referido livro, fica evidente o viés problematizador e libertador da educação: Freire afirma que a educação deve inserir o educando no/com o mundo, de maneira humanizadora.

A problematização, como eixo transformador da/com a sociedade pode ser verificada no trecho a seguir: “[...] o que temos de fazer, na verdade, é propor ao povo, através de certas contradições básicas, sua situação existencial, concreta, presente, como problema, que por sua vez, o desafio e assim lhe exige resposta, não só no nível intelectual, mas no nível da ação" (FREIRE, 2005, p. 86, grifo nosso). Assim, a educação compreende a inserção do sujeito na sociedade, na perspectiva histórica, promovendo o pensamento crítico. Tais princípios convergem para as metodologias ativas da problematização, como recursos práticos, metodológicos, para a formação docente inspirada nos ideais freireanos.

Há que se destacar que o outro tem grande importância na pedagogia de Freire: quem ensina, aprende; quem aprende, ensina também. A problematização dialógica da realidade, base que propomos aqui para a formação docente, tem em vista a democratização dos processos educativos na construção do conhecimento. Por isso, vamos ao encontro de Vigotski (2005), no tocante à importância da interação social na educação: o ser humano só se torna de fato humano socialmente. Assim, em última instância, a formação docente pautada em tais princípios é ampla, abarcando o conhecimento e a partir da problematização.

Do mesmo modo, a figura mitificada do professor não encontra espaço no tipo de formação docente que propomos, já que as relações são horizontalizadas. Em uma formação totalizante, reforçamos que nessa perspectiva o licenciando tome consciência dos diversos elementos que compõem seu percurso formativo. De acordo com Freire (2019C) “[...] é importante vivermos a experiência equilibrada, harmoniosa, entre falar ao educando e falar com ele” (FREIRE, 2019c, p. 83).

Nesse ínterim, cabe perceber a oposição do “penso, logo existo" de René Descartes, na concepção freireana: "É na prática de experimentarmos as diferenças que 


\section{-Revista de Iniciação à Docência, v.6, n.2, 2021- \\ Publicação: dezembro, 2021 - ISSN 2525-4332}

nos descobrimos como eus e tus. A rigor, é sempre o outro enquanto tu que me constitui como eu na medida em que eu, como tu do outro, o constituo como eu" (FREIRE, 2019C, p. 97). Enquanto Descartes condiciona a existência à consciência individual de si mesmo, Freire condiciona a existência à prática, mas não individual, e sim social. Assim, só existo porque sou o tu do outro. A prática social, no mundo concreto, é a base do pensamento freireano; é, portanto, a base dos processos de formação docente.

Assim, consideramos o diálogo dialético como um elemento importante para a formação docente, em um processo contínuo de contextualização da realidade e de problematização, tanto de questões relativas à própria escola e ao ofício de ensinar quanto de questões do mundo em geral, de maneira a fomentar o pensamento crítico. "Mas o posicionamento do sujeito frente a esta realidade, numa perspectiva dialógica, deve vir acompanhado da problematização. Assim, Freire visa propor a situação existencial [do sujeito] como problema, que o desafia, exigindo-lhe resposta no campo da razão e da ação" (TRÉZ, 2011, p. 60).

Assim, o diálogo é dialético e também problematizador. Dessa forma, antes de passarmos propriamente ao método de Paulo Freire, e por conseguinte aos 3MP, de Delizoicov; Angotti; Pernambuco (2002), é importante sublinharmos que o diálogo está na base de todos os processos educativos: é um elemento-chave. Ou seja, está presente em todos os momentos, perspectivando a educação humanizadora e libertadora, em oposição à concepção bancária de educação: "O mundo humano é, dessa forma, um mundo de comunicação” (FREIRE, 12019 b, p. 84). É possível dizer que a partir do diálogo dialético e problematizador, em uma convivência não hierarquizada, que se criam possibilidades para a emancipação do sujeito. É assim, coletivamente, que se torna possível o fomento da curiosidade epistemológica na formação docente. Desse modo, problematiza-se a realidade e propiciam-se condições para a leitura de mundo.

Na proposição e organização de uma formação docente pautada nos princípios de Paulo Freire, tomamos por base o livro Pedagogia do Oprimido. A partir desse referencial, delineamos o seguinte percurso: "Levantamento Preliminar", "Análise das Situações Significativas e Escolha das Codificações", "Diálogos Descodificadores" e a "Redução Temática", sendo que é nessa última etapa que se dá a delimitação dos "Temas Geradores". Assim, de forma coletiva, dialógica e dialética, é possível realizar um estudo problematizador da realidade durante a formação docente. "O diálogo fundamental entre professor e aluno não é um diálogo simplesmente funcional, mas passa pelo diálogo existencial com o mundo" (FREIRE, 2019b, p. 20).

Freire (2005) elucida que a codificação, na prática coletiva, consiste em identificar a contradição, a qual pode ser percebida na realidade por meio de um desenho, uma descrição ou uma fotografia. "As codificações são, então, o objeto que, mediatizando os sujeitos descodificadores, se dá à sua análise crítica" (FREIRE, 2005, p. 125). A fim de superar a curiosidade ingênua e também o desinteresse, a formação docente pautada 


\section{-Revista de Iniciação à Docência, v.6, n.2, 2021- \\ Publicação: dezembro, 2021 - ISSN 2525-4332}

nos princípios freireanos inicia pela problematização. Assim, por meio da investigação científica, do diálogo dialético e problematizador, por meio de etapas metodicamente planejadas, é possível desnaturalizar os fenômenos sociais, substituir explicações do senso comum por princípios causais, a fim de se chegar a uma consciência crítica emancipadora. Para tanto, além do diálogo, são necessários outros princípios freireanos na formação docente: construção compartilhada do conhecimento, amorosidade, convivência não hierarquizada e emancipação.

Para o princípio da problematização, a análise em conjunto da realidade concreta é necessária, a fim de que se estabeleçam situações-problema a serem trabalhadas. Dessa forma, não são conteúdos isolados e descontextualizados, mas sim problemas concretos que se tornam articuladores da formação docente, em uma perspectiva em que teoria e prática tornam-se inseparáveis. Ou seja, a partir da realidade, da prática, recorre-se à teoria, para depois, novamente, retornar à realidade, com um olhar crítico, a fim de construir um ideário democrático. Portanto, não se retorna à realidade para se adaptar a ela, mas sim para transformá-la. Nesse sentido, a ética é um elemento presente em todo o processo, a ser discutido e vivido ao longo da formação docente.

Cabe destacar que o próprio Paulo Freire preferia que não fosse dada ênfase no aspecto utilitário do seu método, cujo slogan era "alfabetização em 40 horas". Mas, sim, no caráter de emancipação do sujeito, portanto, uma educação libertadora, crítica, de forte viés político. Reiteramos o aspecto político e revolucionário das ideias freireanas. Assim, como não foi uma prática cristalizada pelo egrégio professor brasileiro, o método de alfabetização, ao ter a lógica adaptada à formação docente, permite ajustes. Nesse sentido, tendo por base um currículo globalizante/integrado, para organizá-lo em blocos temáticos, propomos os 3MP, de Delizoicov; Angotti; Pernambuco (2002). Essa abordagem temática freireana, inicialmente publicada em livros no final dos anos de 1980 e início da década seguinte, direcionava ensino de ciências e de física no ensino médio. Os referidos autores, ao realizarem uma transposição das ideias de Paulo Freire para a sala de aula, inspiraram diversas iniciativas posteriores. Assim sendo, novas sínteses e apropriações da obra freireana foram realizadas no tangente às questões metodológicas e curriculares. Nessa perspectiva, realizamos uma interlocução entre os 3MP (DELIZOICOV; ANGOTTI; PERNAMBUCO, 2002) e a formação docente, orientando uma concepção curricular globalizante/integrada tendo por base os temas geradores de Paulo Freire.

O entendimento sobre a dinâmica dos 3MP aponta para uma concepção curricular e metodológica não engessada, para além da pedagogia tradicional e vislumbrando a possibilidade de adequações e adaptações ao contexto específico de cada instituição escolar. Metodologicamente, os temas geradores emergem da investigação temática. Assim, um programa organizado a partir de um tema central pode organizar a formação docente. 


\section{-Revista de Iniciação à Docência, v.6, n.2, 2021- \\ Publicação: dezembro, 2021 - ISSN 2525-4332}

A problematização inicial é o momento em que se apresentam:

[...] situações reais que os alunos conhecem e presenciam e que estão envolvidas nos temas, embora também exijam, para interpretá-las, a introdução dos conhecimentos contidos nas teorias científicas. [...] A meta é problematizar o conhecimento que os alunos vão expondo, de modo geral, com base em poucas questões propostas relativas ao tema e às situações significativas (DELIZOICOV et al., 2002, p. 200).

Nesse momento, o senso crítico dos educandos é aguçado, a fim de que se distancie das explicações do senso comum e desnaturalize os fenômenos. É o momento de expor opiniões, ouvir, debater e, então, perceber que necessita de mais conhecimentos. O segundo momento pedagógico é constituído pela organização do conhecimento:

[...] os conhecimentos selecionados como necessários para a compreensão dos temas e da problematização inicial são sistematicamente estudados [...] sob a orientação do professor. As mais variadas atividades são então empregadas, de modo que o professor possa desenvolver a conceituação identificada como fundamental para uma compreensão científica das situações problematizadas (DELIZOICOV et al, 2002, p. 201).

Cabe ressaltar que esse momento evidencia a necessidade de superação da disciplinaridade. Portanto, professores e conhecimentos de diversas áreas convergem para a aprendizagem do educando, conscientemente planejada e executada em conjunto a partir da problematização. O último momento é denominado aplicação do conhecimento:

A meta pretendida com este momento é muito mais a de capacitar os alunos ao emprego dos conhecimentos, no intuito de formá-los para que articulem, constante e rotineiramente, a conceituação científica com situações reais, do que simplesmente encontrar uma solução, ao empregar algoritmos matemáticos que relacionam grandezas ou resolver qualquer outro problema típico dos livros (DELIZOICOV et al, 2002, p. 202).

Assim, os 3MP partem da realidade e a ela retornam, caracterizando uma metodologia de formação docente crítica e participativa. Tais momentos encontram respaldo no método de alfabetização de Paulo Freire, que parte do universo simbólico do educando, o qual oferece elementos para a alfabetização. Em uma relação dialética, parte-se do universo simbólico e a ele se retorna, na perspectiva de ressignificá-lo. Metaforicamente, quando se retoma "Eva viu a uva", compreende-se quem é Eva e por que ela viu a uva, quem plantou a parreira de uva, e assim por diante. As relações entre sujeito e o universo que o rodeia são, assim, reinterpretadas. Dessa forma, propomos os $3 \mathrm{MP}$ como um movimento em que se emergem os temas que podem organizar o currículo globalizante/integrado para a formação docente. Metodologicamente, os 3MP podem ser articulados com as metodologias ativas da problematização, as quais serão exploradas a seguir. 


\section{As Metodologias Ativas da Problematização}

Na visão de Berbel (2011), as metodologias ativas promovem criatividade e autonomia nos educandos, já que estes percebem que são a "origem da própria ação, ao serem apresentadas oportunidades de problematização de situações envolvidas na programação escolar, de escolha de aspectos dos conteúdos de estudo, de caminhos possíveis para o desenvolvimento de respostas ou soluções” (BERBEL, 2011, p. 28).

A problematização como ponto de partida para as relações de aprender e ensinar, a aprendizagem através de questionamentos, a dúvida e a indagação na construção do conhecimento são aspectos que têm longa tradição na história da educação. Nogueira (2017), ao discorrer sobre os antecedentes do PBL, elucida: "Nos analectos de Confúcio (500 a. C), onde ele só ajudava seus discípulos depois que eles pensam em determinado tema ou pergunta, tentavam resolver e não conseguiam encontrar as respostas" (NOGUEIRA, 2017, p.12). Remontando ao início das civilizações, a aprendizagem através de problemas encontra-se em Sócrates, através da maiêutica: fazer diversos questionamentos até que o estudante compreenda novas ideias. "Sua crença se fundamenta que através do diálogo os homens chegariam próximos ao conhecimento" (SOUZA, 2020, p. 81).

Não obstante, as metodologias ativas da problematização, como são conhecidas contemporaneamente, foram desenvolvidas na década de 1960, "na Universidade McMaster, no Canadá, e em Maastricht, na Holanda, e em escolas de Medicina, inicialmente" (MORAN, 2019, p. 55). Posteriormente, foram aplicadas nas demais áreas do conhecimento. O médico e professor Howard Barrows foi o principal responsável, ao utilizar pacientes simulados e estudar o raciocínio clínico. Autor de diversas obras, destacamos aqui o livro Problem-Based Learning: An Approach to Medical Education, publicado pela primeira vez em 1980, no qual Barrows apresenta dois princípios básicos para o PBL: o aprendizado baseado na solução de problemas é mais eficaz para criar um arcabouço de conhecimentos, os quais o futuro médico utilizará na prática; para o paciente, as habilidades médicas são mais relevantes que as habilidades mnemônicas (BARROWS; TAMBLYN, 1980).

O referido livro, ao evidenciar as bases científicas do PBL, demonstra que esta se diferencia de outras metodologias porque inicia por um problema, não pelo conteúdo/objeto do conhecimento. É de suma importância destacar que o PBL emergiu da observação, por parte dos professores do curso de medicina, da pouca eficácia das aulas que estavam ministrando. O conhecimento, apenas memorizado pela maioria dos educandos, era em pouco tempo esquecido, o que não garantia a aprendizagem para um médico. Assim, é possível estabelecer um ponto em comum com as ideias de Paulo Freire, sendo que este também criticava a mera transmissão de conhecimento, como se aprender fosse apenas memorizar. 


\section{-Revista de Iniciação à Docência, v.6, n.2, 2021- \\ Publicação: dezembro, 2021 - ISSN 2525-4332}

O PBL e as metodologias ativas, como as conhecemos hoje, surgiram a partir da empiria, da observação por parte dos professores da própria prática, num movimento de ação-reflexão. Por outro lado, consideramos que as metodologias ativas surgiram num momento chave da história da educação, em que as descobertas da psicologia lançavam novas luzes aos processos de ensino e aprendizagem, como a Psicologia Cognitiva, de Jerome Bruner (MARQUES, 2000).

Portanto, apontamos para o uso das metodologias ativas tendo como arcabouço teórico as ideias de Paulo Freire, já que a problematização (e por extensão o dialogismo) pode ter objetivos diferentes, dependendo de cada autor e vertente teórica. Sendo assim, o caráter político e revolucionário das ideias freireanas, na construção da democracia, perpassa o uso das metodologias ativas na formação docente. Estando em consonância com o arcabouço teórico-metodológico freireano, outro ponto em comum é a motivação, condição imprescindível para o sucesso dos processos educativos, os quais conduzem à emancipação por meio da ação-reflexão. Construindo, portanto, um sujeito autônomo. Através da problematização e da contextualização, abre-se a possibilidade de ir além da fragmentação do conhecimento e da aprendizagem mecânica.

Como os temas geradores emergem dos próprios educandos, na perspectiva de Paulo Freire, os quais são alcançados através da Investigação Temática, contemplando a visão de mundo dos sujeitos que refletem situações-limite, fruto das situações de opressão vivenciadas, em uma visão problematizadora da realidade, o centro dos processos de ensino e aprendizagem é o educando. Eis, assim, um importante ponto em comum entre Paulo Freire e as metodologias ativas, mais especificamente o PBL: consoante Simon (2014), "[...] a Aprendizagem Baseada em Problemas (Problem Based Learning - PBL) é um método centrado no estudante [...]” (SIMON, 2014, p. 1358).

A base das metodologias ativas da problematização está na contextualização, que parte da experiência concreta do sujeito. Dessa forma, os 3MP estão em consonância com tais metodologias: são uma forma de organizar os blocos temáticos curriculares e, ao mesmo tempo, metodologia de ensino e de aprendizagem, de forma articulada com a problematização. A fim de superar a pedagogia tradicional na formação docente, a problematização contempla as seguintes características metodológicas: trazer consigo uma contradição; ser coletiva; trazer uma situação real ou muito próxima do real. Tais características são atribuídas, por aproximação, a partir dos temas geradores, na perspectiva do diálogo dialético e problematizador. Nesse sentido, reforçamos com as palavras de Freire (2019C):

A rigor, é inviável o trabalho formador, docente, que se realize num contexto que se pense teórico, mas, ao mesmo tempo, faça questão de permanecer tão longe do e indiferente ao contexto concreto, ao mundo imediato da ação e da sensibilidade dos educandos (FREIRE, 2019c, p. 99). 


\section{-Revista de Iniciação à Docência, v.6, n.2, 2021- \\ Publicação: dezembro, 2021 - ISSN 2525-4332}

Nessa perspectiva, apresentamos duas metodologias ativas que envolvem problematização: Aprendizagem baseada em problemas ( $P B L$ ) e Problematização utilizando o arco de Mangarez.

Aprendizagem baseada em problemas ou problem based learning ( $P B L$ ) - tem a vantagem de integrar teoria e prática na formação docente, promovendo a reflexão. Tem como características principais: “1) a aprendizagem significativa; 2) a indissociabilidade entre teoria e prática; 3) o respeito à autonomia do estudante; 4) o trabalho em pequeno grupo; 5) a educação permanente; 6) avaliação formativa" (BATISTA; BATISTA, 2009, p. 1183). O PBL foi desenvolvido no ensino superior, em cursos relacionados à área da saúde, como explicita o excerto a seguir:

O PBL foi primeiramente instituído na Faculdade de Medicina da Universidade de
McMaster (Canadá), na década de sessenta. No Brasil, as instituiçães
precursoras na implantação desta modalidade de estrutura curricular foram a
Faculdade de Medicina de Maŕlia, em 1997, e o Curso de Medicina da
Universidade Estadual de Londrina, em 1998. No Estado do Rio de Janeiro, o
curso de graduação em Medicina da Fundação Educacional Serra dos Órgãos
(FESO) - atual Centro Universitário Serra dos Órgãos (UNIFESO) - foi pioneiro
em um contexto de adoção curricular de metodologias ativas de ensino-
aprendizagem, em 2005" (BATISTA; BATISTA, 2007, p. 1184).

Em certos casos, como mencionado acima, o PBL reorganizou a grade curricular, tornando-se um dos princípios da formação, passando de um currículo de coleção para um currículo globalizante/integrado. Ao comentar sobre a implantação do PBL na Universidade Estadual de Feira de Santana, Almeida (2015) posiciona-se de maneira positiva, indicando que os objetivos foram alcançados, destacando a criação de espaços formativos diferenciados, além da autonomia dos educandos. Também sobre os benefícios do PBL para a formação dos educandos, Cabral e Almeida (2014) assim se manifestam: "[...] os alunos formados por esta metodologia são mais independentes e possuem rotina de estudos mais efetiva quando comparados a alunos formados por métodos tradicionais" (CABRAL; ALMEIDA, 2014, p. 02).

Gemignani (2012) elenca os passos para o PBL: “Após análise inicial do problema, os estudantes definem seus objetivos de aprendizagem e buscam as informações necessárias para abordá-lo. Após, discutem o que encontraram e compartilham o que aprenderam" (GEMIGNANI, 2012, p. 13) Assim, perspectivando a formação docente, diversos problemas reais ou muito próximos da realidade podem ser elencados: indisciplina na escola; educandos com dificuldades na alfabetização, relações de gênero e sexualidade, entre outros. Definido o problema e os objetivos, as informações que os educandos vão buscar podem se relacionar às mais diversas áreas do conhecimento. Lembrando que a definição dos problemas se articula anteriormente, em uma etapa inicial, em que são aplicados os 3MP, a partir dos quais se organiza o currículo, em blocos temáticos.

Se a partir dos $3 \mathrm{MP}$ surgiu como problema a dificuldade de alfabetizar uma criança, por exemplo: o que a análise do aspecto psicológico diz? E a psicolinguística? As 


\section{-Revista de Iniciação à Docência, v.6, n.2, 2021- \\ Publicação: dezembro, 2021 - ISSN 2525-4332}

relações socioeconômicas também interferem? Historicamente, como a educação brasileira tratou o tema alfabetização? O que as pesquisas científicas mais recentes podem elucidar sobre a alfabetização? Decodificação, letramento, literacia, entre outros termos, que impacto possuem na prática? Assim, através da problematização, a formação docente também se pauta na pesquisa, na investigação, sendo que as diversas áreas do conhecimento convergem para a solução de um problema.

A nível internacional, Freeman et al. (2014) compararam o resultado de avaliações de alunos da graduação em ciências, tecnologias, matemática e engenharias: os pesquisadores identificaram que os graduandos pelo método tradicional erraram 1,5 vez mais que os graduandos pelas metodologias ativas. Tal dado aponta para o aspecto significativo da aprendizagem a partir de problemas.

A segunda metodologia ativa da problematização que apresentamos é esta: Problematização utilizando o Arco de Mangarez. Tal metodologia possui esse nome porque parte da realidade e a ela retorna, visualmente formando um arco. Constituído por cinco momentos, o método foi desenvolvido na década de 1960 por Charles Maguerez e adaptado por Bordenave (1989). Metodologicamente, funciona da seguinte maneira: observação da realidade e identificação da problemática, levantamento de pontos-chave, teorização, hipóteses de solução e aplicação à realidade.

Se no PBL o problema pode ser real ou hipotético, na Problematização utilizando o arco de Mangarez presume-se um problema eminentemente real, identificado pelos educandos na realidade observada. Sugerimos que seja a partir dos $3 \mathrm{MP}$ e da organização dos blocos temáticos curriculares; por conseguinte, a realidade é recortada, ao ser identificada uma problemática, e é a partir desta que se desenvolve a teoria e os conceitos. Informações são coletadas, surgem hipóteses e chega-se à solução, que retorna à realidade. Assim, no PBL corre-se o risco de os problemas artificiais não fazerem sentido para o educando.

É importante salientar que, orientado pela perspectiva freireana, todo o processo parte da prática e a ela retorna, mas não em uma posição passiva, de aceitação para a realidade: retorna-se à realidade para transformá-la. Assim, nas palavras de Paulo Freire: “A prática de pensar a prática, de estudar a prática, nos leva à percepção da percepção anterior ou ao conhecimento do conhecimento anterior que, de modo geral, envolve um conhecimento" (FREIRE, 2019c, p. 118).

Na Problematização utilizando o arco de Mangarez, destacamos a experiência da Faculdade de Medicina de Botucatu, que criou em 2003, como um programa, mas passou a ser em 2007 uma disciplina interprofissional: a problematização em educação em saúde. Inicialmente, agregava graduandos de medicina e de enfermagem. Sobre esta experiência, Villardi (2015) assim se manifesta:

Para tanto, utilizam "novos referenciais" problematizadores para a educação na área da Saúde, como a metodologia da problematização com o arco de Maguerez, que promove a mobilização do potencial social, político e ético dos 


\section{-Revista de Iniciação à Docência, v.6, n.2, 2021- Publicação: dezembro, 2021 - ISSN 2525-4332}

alunos, os quais são levados a observar a realidade de maneira atenta e a identificar o que se mostra preocupante, e concretiza-se através de um processo criativo que envolve ação-reflexão sobre um aspecto da realidade observada, o que implica realizar alguma transformação nela (VILLARDI, 2015, p. 18).

Nesse sentido, a Problematização utilizando o arco de Mangarez serviu para unir/mobilizar profissionais de áreas afins em torno de situações-problema. Transpondo tal movimento da área da Saúde para a Educação, pressupomos que a formação docente também poderia promover movimentos pedagógicos entre os licenciandos - com vistas à mobilização do potencial social, político e ético dos mesmos, num processo de açãoreflexão-ação.

Ao partir da realidade concreta do educando, a Problematização utilizando o arco de Mangarez valoriza os conhecimentos prévios, estimulando a criatividade e a ação espontânea, a curiosidade epistemológica e a pesquisa. Nessa perspectiva, a construção compartilhada do conhecimento se faz presente em todo o percurso da formação docente. É importante destacar que para Freire (2005): “Quanto mais se problematizam os educandos, como seres no mundo e com o mundo, tanto mais se sentirão desafiados. Tão mais desafiados, quanto mais obrigados a responder ao desafio" (FREIRE, 2005, p. 98).

Vale sinalizar que as metodologias da problematização requerem planejamento detalhado e articulado entre os docentes. A organização de blocos temáticos a partir dos 3MP, como uma maneira de organizar o currículo integrado/globalizante, necessita ser cuidadosa e criteriosa. Nesse contexto, torna-se necessário repensar as formas de avaliação também. Uma avaliação formativa, ao longo do processo de formação docente, parece ser o mais indicado. Afinal, as metodologias a partir de um currículo globalizante/integrado também pressupõem uma avaliação condizente. Na perspectiva de Cunha (1996), “[...] a avaliação adquirirá cada vez mais uma dimensão valorativa, integradora e emancipatória. Deverão ser adotados múltiplos critérios de avaliação para favorecer e valorizar as diferentes possibilidades do aluno" (CUNHA, 1996, p. 22).

\section{À Guisa de Conclusão}

Por muito tempo, a humanidade utilizou a prática como única forma de aprendizagem: a caça e a pesca, por exemplo, eram aprendidas empiricamente, com os mais jovens acompanhando os mais velhos. Nas comunidades tradicionais, o trabalho de parteira, por exemplo, era aprendido pela moça que auxiliava. O desenvolvimento científico proporcionou a teoria, que é oriunda da prática. Assim, o que propomos é uma formação docente que não dissocie teoria e prática, mas que por meio da dialogicidade problematizadora proporcione a reflexão crítica e a emancipação dos educandos.

Reiteramos que as metodologias ativas da problematização, em diálogo com Paulo Freire, requerem um processo dialógico contínuo de construção, que perpassa também as discussões sobre currículo. Aplicar o passo a passo do PBL, por exemplo, de 


\section{-Revista de Iniciação à Docência, v.6, n.2, 2021- \\ Publicação: dezembro, 2021 - ISSN 2525-4332}

maneira aleatória, pode não trazer à tona todas as dimensões de uma educação de inspiração freireana. Assim, defendemos a necessária superação da pedagogia tradicional, bem como o currículo fragmentado, em que as unidades curriculares têm um fim em si mesmas, como escolha política nos processos de formação de professores.

Consideramos também que a organização curricular que propomos, baseada na perspectiva globalizante/integrada é uma possibilidade dentre diversas outras, já exploradas, a partir do referencial teórico de Paulo Freire, como a Abordagem Temática Freireana; esta propõe um processo pautado nos temas geradores, a partir dos quais os conteúdos serão selecionados. Assim, relacionamos as metodologias ativas da problematização aos 3MP, a fim de que as situações-problema do PBL e do arco de Manguerez tenham como inspiração o ideário freireano e que tais situações façam sentido para o educando. O que propomos, assim, vem a ser mais uma possibilidade, dentre diversas apropriações e sínteses das ideias de Paulo Freire.

Outrossim, chamamos a atenção para o fato de que a formação docente não se dá apenas pelo método, mas sim por uma formação política também. Nesse sentido, Villardi (2015) assinala que: "A utilização mecânica e sem apropriação adequada dos fundamentos e das implicações das práticas problematizadoras pode apoiar-se em uma relação superficial e verticalizada entre professores, alunos e a realidade investigada [...]." (VILLARDI, 2015, p. 20). Assim, enquanto inspiração política e até mesmo revolucionária para a formação docente, tomamos Paulo Freire; enquanto organização didática, apontamos uma possibilidade dentre diversas outras: os 3MP (DELIZOICOV et al, 2002, p. 202), a serem articulados com as metodologias ativas da problematização (PBL e Problematização pelo arco de Mangarez), princípios que apontam para um currículo globalizante/integrado. Elementos esses que podem vir a fomentar a criticidade do futuro professor, ressignificando a própria experiência, em uma formação docente para além do alinhamento constado na legislação que rege as políticas educacionais.

As metodologias da problematização não devem estar a serviço, portanto, apenas da aquisição de conhecimentos ou de habilidades e competências, como orientam os mais recentes documentos emanados pelo $M E C$, mas sim atreladas à formação política e ética do docente. A princípio, as metodologias ativas surgiram como uma forma de aperfeiçoar a formação dos médicos; portanto, não é possível afirmar que são oriundas de uma teoria educacional específica, ou uma concepção pedagógica. Eis aí um afastamento das ideias freireanas, que enfatizam sobretudo o caráter político e revolucionário da educação. Por isso propomos aqui o embasamento das metodologias no ideal de Paulo Freire, notadamente nos três momentos pedagógicos (DELIZOICOV; ANGOTTI; PERNAMBUCO, 2002), em um currículo globalizante/integrado.

Temos em vista uma formação crítica, que permita ao professor refletir sobre a prática e ressignificar a própria formação, quebrando o ciclo da mimese na educação básica, ou seja, repetindo as mesmas práticas que vivenciou, sem reflexão teórica. Nesse 
-Revista de Iniciação à Docência, v.6, n.2, 2021-

Publicação: dezembro, 2021 - ISSN 2525-4332

sentido, reforçamos o fator dialético que Paulo Freire imprimiu à própria teoria. Nesse contexto, refletimos também sobre o papel do professor:

O professor deve ensinar. É preciso fazê-lo. Só, porém, que ensinar não é transmitir conhecimento. Para que o ato de ensinar se constitua como tal é preciso que o ato de aprender seja precedido do ou concomitante ao ato de apreender o conteúdo ou o objeto cognoscível, com que o educando se torna produtor também do conhecimento que Ihe foi ensinado" (FREIRE, 2019c, p. 175).

Assim, ao tornar-se produtor, o educando ressignifica o conhecimento, que o instrumentaliza para a prática, com o objetivo final de transformação da realidade. Desse modo, é preciso emergir da cotidianidade, distanciar-se dos fenômenos naturalizados e, com olhar curioso, ressignificar a formação de professores. Tais referenciais foram adotados, especialmente, porque as metodologias ativas podem ser encaradas como meras técnicas de ensino, isoladas, ou como "receitas" prontas para serem aplicadas. Por isso, o ideal freireano a embasá-las é importante, no sentido de uma formação política do futuro professor, para que possa perceber a complexidade dos processos educativos, para além de relações superficiais, como se apenas o método fosse a "fórmula mágica" da educação. Exploramos também as questões curriculares, nos limites deste trabalho, tendo em vista que divergências e outros olhares podem ser construídos a partir de outros pesquisadores e trabalhos futuros.

Por fim, reiteramos que os princípios freireanos, notadamente no que tange à educação popular, podem ser o polo catalisador das metodologias da problematização, a fim de formar o docente autônomo, consciente e crítico. Nos limites de um artigo, abordamos duas metodologias ativas a partir da problematização, contudo há outras possibilidades, como a aprendizagem baseada em projetos, aprendizagem baseada em times, ou team based learning (TBL), entre inúmeras perspectivas de trabalho em grupo, tendo como ponto central a problematização.

Acreditamos que tais reflexões podem desencadear diversas outras possibilidades de organização curricular da formação docente, tendo como percurso metodológico as metodologias ativas, a partir do diálogo dialético e problematizador. Afinal, temos em vista que para romper com o "Eva viu a uva” na educação básica, seja necessário repensar a formação docente, esta sendo abrangente e com teoria e prática articuladas, tendo como fim maior a transformação social, na construção de uma sociedade mais justa e fraterna.

\section{Referências}

ALMEIDA, E. C. S. DE. Aprendizagem na educação superior: a auto-trans-formação do estudante na Aprendizagem Baseada em Problemas (Problem-Based Learning-PBL). 2015. 167fls. Dissertação (Mestrado em Educação) - Programa de Pós-Graduação da Universidade Estadual de Feira de Santana, Feira de Santana, 2015.

ANASTASIOU, L. G. C.; ALVES, L. P. (orgs.) Processos de ensinagem na universidade: pressupostos para as estratégias de trabalho em aula. Joinville, SC: Univille, 2005. 
APPLE, M. W.; BEANE, J. A. (orgs). Escolas democráticas. São Paulo: Cortez, 1997.

BATISTA, R. S.; BATISTA, R. S. Os anéis da serpente: a aprendizagem baseada em problemas e as sociedades de controle. Ciência \& Saúde Coletiva, Rio de Janeiro, v. 14, n. 4, p. 1183-1192, 2009.

BERBEL, N. A. N. As metodologias ativas e a promoção da autonomia de estudantes.

Seminário: Ciências Sociais e Humanas, v. 32, n. 1, p. 25-40, 2011. Disponível em: https://edisciplinas.usp.br/pluginfile.php/5437015. Acesso em: 17 jun. 2021.

BERBEL, N. A. N. Metodologia da problematização: fundamentos e aplicações. Londrina: EDUEL, 1999.

BERNSTEIN, B. Class, codes and Control, Vol. III: Towards a theory of educational transmissions. Londres: Routledge \& Kegan Paul, 1977.

BORDENAVE, J. D.; PEREIRA, A. M. Estratégias de ensino aprendizagem. 4. ed. Petrópolis: Vozes, 1989.

BRASIL. Lei n. 9.394 de 20 de dezembro de 1996. Estabelece as diretrizes e bases da educação nacional. Brasília, DF: Presidência da República, 1996. Disponível em: http://www.planalto.gov.br/ccivil_03/leis/L9394.htm. Acesso em: 12 out. 2020.

BRASIL. Ministério da Educação. Base Nacional Comum Curricular, BNCC. Brasília, 2017.

BRASIL. Ministério da Educação. Lei de Diretrizes e Bases da Educação Nacional, LDB. Brasília, 1996.

BRASIL. Resolução CNE/CP n. 2, de 20 de dezembro de 2019. Define as Diretrizes Curriculares Nacionais para a Formação Inicial de Professores para a Educação Básica e institui a Base Nacional Comum para a Formação Inicial de Professores da Educação Básica (BNC-Formação), 2019. Disponível em: http://portal.mec.gov.br/index.php?option=com_docman\&view=download\&alias=135 951-rcpo02-19\&category_slug=dezembro-2019-pdf\&Itemid=30192. Acesso em: 12 jun. 2021.

BRASIL. Resolução $N^{\circ} 1$, de 27 de outubro de 2020. Dispõe sobre as Diretrizes Curriculares Nacionais para a Formação Continuada de Professores da Educação Básica e institui a Base Nacional Comum para a Formação Continuada de Professores da Educação Básica (BNC-Formação Continuada). Brasília, 2020.

CABRAL, H. S. R.; ALMEIDA, K. K. V. G. A. Problem based learning: aprendizagem baseada em problemas. Revista Interfaces: Saúde, Humanas e Tecnologia, v. 2, n. 4, 2014.

Disponível em: https://interfaces.leaosampaio.edu.br/index.php/revista-interfaces/about. Acesso em: 21 jul. 2021.

CALDARELLI, P. G. A importância da utilização de práticas de metodologias ativas de aprendizagem na formação superior de profissionais da saúde. Sustinere, v. 5, n. 1, p. 175178, 2017. Disponível em: http://www.e-

publicacoes.uerj.br/index.php/sustinere/article/view/26308. Acesso em 14 de out. de 2020.

DELIZOICOV, D.; ANGOTTI, J. A. ; PERNAMBUCO, M. M. Ensino de ciências: fundamentos e métodos. 3. ed. São Paulo: Cortez, 2002.

DEWEY, J. Vida e Educação. São Paulo: Nacional, 1959. 
FREEMAN, S. et al. Active learning increases student performance in science, engineering, and mathematics. Proceedings of the National Academy of Sciences, v. 111, n. 23, p. 84108415, 2014.

FREIRE, P. Aprendendo com a própria história: Paulo Freire, Sérgio Guimarães. 2. ed. Rio de Janeiro/São Paulo: Paz e Terra, 2019a.

FREIRE, P. Extensão ou Comunicação? 21. ed. Rio de Janeiro/São Paulo: Paz e Terra, 2019b.

FREIRE, P. Pedagogia do Oprimido. 40. ed. Rio de Janeiro: Paz e Terra, 2005.

FREIRE, P. Professora, sim; tia, não: cartas a quem ousa ensinar. 28. ed. Rio de Janeiro/São Paulo: Paz e Terra, 2019c.

FREITAS, L. C. A reforma empresarial da educação: nova direita, velhas ideias. São Paulo: Expressão Popular, 2018.

GIL, A. C. Métodos e técnicas de pesquisa social. 4. ed. São Paulo: Atlas, 1994.

GIOLO, J. Educação a Distância no Brasil: a expansão vertiginosa. Revista Brasileira de Política e Administração da Educação, v. 34, n. 1, p. 73-97, 2018. Disponível em: https://seer.ufrgs.br/rbpae/article/view/82465/48878. Acesso em: 12 jul. 2021.

MARQUES, R. A pedagogia de Jerome Bruner. 2000. Disponível em: <http://www.eses.pt/usr/ramiro/docs/etica_pedagogia/A\%20Pedagogia\%20de\%20JeromeB runer.pdf>. Acesso em: 20 jul. 2018

MORAIS, A. C. L. de. Metodologia Ativa: uma experiência no ensino superior com modelo do Ensino Híbrido. In: MARTINS, Gercimar (org). Metodologias ativas: a caixa preta da Educação. Quirinópolis: Editora IGM, 2019.

MORAN, J. Metodologias Ativas de Bolso: como os alunos podem aprender de forma ativa, simplificada e profunda. São Paulo: Editora do Brasil, 2019.

POTT, E. T. B.; JUNIOR, H. P. Mapeando os estudos sobre educação médica no Brasil: Tendências e perspectivas. Sustinere, v. 7, n. 1, p. 132-152, 2019. Disponível em: http://dx.doi.org/10.12957/sustinere. Acesso em: 17 jul. 2021.

REIS FILHO, C. A educação e a ilusão liberal. 2. ed. Campinas: Autores Associados, 1995.

RIBEIRO, M. Volta às aulas no País e acesso à internet não são temas do MEC, diz ministro. Jussara Soares, O Estado de S. Paulo. São Paulo, ano 145, n. 46.231, 24 set. de 2020. Disponível em: https://educacao.estadao.com.br/noticias/geral. Acesso em: 11 mai. 2021.

ROMAN, C.; et al. Metodologias ativas de ensino-aprendizagem no processo de ensino em saúde no Brasil: uma revisão narrativa. Clinical And Biomedical Research, v. 37, n.4, p. 349-357, 2017. Disponível em: https://seer.ufrgs.br/index.php/hcpa/article/view/7391. Acesso em: 17 de outubro de 2020.

SANTOS, J. C. R.; et al. Metodologias ativas e interdisciplinaridade na formação do nutricionista. Semina: Ciências Sociais e Humanas, v. 38, n. 1, p. 117-128, 2017. Disponível em: http://www.uel.br/revistas/uel/index.php/seminasoc/article/view/28205. Acesso em: 18 de jun. 2021. 
SANTOS, M. I. M; CABRAL, C. D. S. R; BRITO, C. E. N. Metodologias Ativas de aprendizagem na educação básica: relatos da experiência de uma escola particular em Sergipe. In: MARTINS, Gercimar (org). Metodologias ativas: a caixa preta da Educação. Quirinópolis: Editora IGM, 2019.

SIMON, E. Metodologias ativas de ensino-aprendizagem e educação popular: encontros e desencontros no contexto da formação dos profissionais de saúde. Revista Interface, v. 18, n. 2, p. 1355-1364, 2014. Disponível em: https://www.researchgate.net/journal/Interface-Comunicacao-Saude-Educacao. Acesso em: 25 mar. 2020.

SPOHR, F. S. DALSOTTO, M. P. B.; CORREA, Y. Educação Popular e Pedagogia Crítica: os princípios pedagógicos freireanos na formação de Educadores Populares em Saúde.

Práxis Educativa, v. 16, e2116613, p. 1-19, 2021 Disponível em:

<https://www.revistas2.uepg.br/index.php/praxiseducativa. Acesso em: 17 jul. 2021.

TRÉZ, T. A.. Experimentando a desumanização: Paulo Freire e o uso didático de animais. Revista Brasileira de Ensino de Ciência e Tecnologia, v. 4, n. 2, p. 50-66, 2011. Disponível em: https://periodicos.utfpr.edu.br/rbect/article. Acesso em: 21 jul. 2021.

VIGOTSKI, L. S . Pensamento e Linguagem. 3. ed. São Paulo: Martins Fontes, 2005.

VILLARDI, M. L. A problematização em educação em Saúde: percepções dos professores tutores e alunos. São Paulo: Cultura Acadêmica, 2015. 